\title{
Behavioural modes in butterflies: their implications for movement and searching behaviour
}

Article

Accepted Version

Creative Commons: Attribution-Noncommercial-No Derivative Works 4.0

Evans, L. C. ORCID: https://orcid.org/0000-0001-8649-0589, Oliver, T. H., Sims, I., Greenwell, M. P., Melero, Y., Watson, A., Townsend, F. and Walters, R. J. (2020) Behavioural modes in butterflies: their implications for movement and searching behaviour. Animal Behaviour, 169. pp. 23-33. ISSN 0003-3472 doi: https://doi.org/10.1016/j.anbehav.2020.09.001 Available at https://centaur.reading.ac.uk/93155/

It is advisable to refer to the publisher's version if you intend to cite from the work. See Guidance on citing.

Published version at: https://doi.org/10.1016/j.anbehav.2020.09.001

To link to this article DOI: http://dx.doi.org/10.1016/j.anbehav.2020.09.001

Publisher: Elsevier

All outputs in CentAUR are protected by Intellectual Property Rights law, including copyright law. Copyright and IPR is retained by the creators or other copyright holders. Terms and conditions for use of this material are defined in the End User Agreement. 


\section{CentAUR}

Central Archive at the University of Reading

Reading's research outputs online 
Luke Christopher Evans ${ }^{\mathrm{a}}$, Tom Henry Oliver ${ }^{\mathrm{a}}$, Ian Sims ${ }^{\mathrm{b}}$, Matthew Peter Greenwell ${ }^{\mathrm{a}}$, Yolanda

4 Melero $^{\mathrm{a}, \mathrm{c}}$, Arron Watson ${ }^{\mathrm{a}}$, Felix Townsend ${ }^{\mathrm{a}}$, Richard John Walters ${ }^{\mathrm{d}}$

5 a School of Biological Sciences, University of Reading, Harborne Building, Reading,

6 Berkshire RG6 6AS, UK

7 b Syngenta, Jealott's Hill International Research Centre, Bracknell, U.K.

8 c CREAF, Cerdanyola del Vallés, Spain

9 d Centre for Environmental and Climate Research, University of Lund, Lund, Sweden

Received 1 May 2020

Initial acceptance 8 July 2020

Final acceptance 11 August 2020

MS number 20-00314

Correspondence: L. C. Evans, School of Biological Sciences, University of Reading, Harborne Building, Reading, Berkshire RG6 6AS, UK

E-mail address: Lukechristopher.evans@ @reading.ac.uk (

(L. C. Evans)

Animals move in 'modes' where movement patterns relate to specific behaviours. Despite much work on the movement of butterflies, their behavioural modes are relatively unexplored. Here we analysed the behaviour of the model butterfly species the meadow brown, Maniola jurtina. We identified modes in both sexes and across habitats varying in resource density. We found that, in nectar-rich habitats, males had more diverse behaviour than females, engaging in a unique 'high-flight' mode associated with mate search, whereas females were primarily nectaring or inactive. In nectar-poor habitats, both sexes were similar, switching between flight and inactivity. We also identified the movement parameters of the modes, finding that, for both sexes, movements associated with nectaring were slower and more tortuous and, for males, the mode associated with mate searching was straighter and faster. Using an individual-based random-walk model, we investigated the effects of 
behaviour on movement predictions by comparing a mode-switching model with a version including intraspecific variation and another assuming homogeneity between individuals. For both sexes, including modes affected the mean and shape of the displacement rate compared to models assuming homogeneity, although for females modes increased displacement 1.5 times while for males they decreased it by a third. Both models also differed substantially from models assuming intraspecific variation. Finally, using a new model of search behaviour we investigated the general conditions under which individuals should engage in an exclusive search for host plants or receptive females. Parameterized for $M$. jurtina, the model predicted males should engage exclusively in mate search, but females only when searching is very efficient. The model provides a framework for analysing the searching behaviour of other butterfly species.

Keywords: Maniola jurtina, meadow brown, motivation, movement

A fundamental aspect of the behaviour of an animal is the way it moves through its environment. Movement is evaluated from several standpoints (sensu Tinbergen 1963) varying from the mechanistic or biomechanical (e.g. animal locomotion; Alexander, 2003) to considerations of adaptive purpose (e.g. optimality; Charnov, 1976). Current research in movement ecology intersects these areas (Holyoak, Casagrandi, Nathan, Revilla, \& Spiegel, 2008), linking the observed movement of individuals to the motivational states that underpin them (Nathan et al., 2008). A key assumption of much recent modelling is that animals switch between distinct movement patterns, often referred to as 'modes', as a result of the local environment and their motivation (Fryxell et al., 2008; Morales \& Ellner, 2002; Morales, Haydon, Frair, Holsinger, \& Fryxell, 2004; Skalski \& Gilliam, 2003). Here modes refer to temporally and spatially correlated movement patterns adapted to achieving a specific 
goal (e.g. foraging). Identifying modes offers many benefits: first, it allows quantification of the features of a behaviour (Jonsen, Myers, \& James, 2006; Weimerskirch et al., 2002); second, it links behaviours to the distribution of individuals across landscapes (Börger, Dalziel, \& Fryxell, 2008; Singh, Börger, Dettki, Bunnefeld, \& Ericsson, 2012); and third, the optimality of the movement patterns for their inferred purpose can be examined (Avgar, Kuefler, \& Fryxell, 2011; Dias, Granadeiro, \& Palmeirim, 2009; Louzao, Wiegand, Bartumeus, \& Weimerskirch, 2014). However, linking movement modes with their associated behaviours is challenging, as the accompanying behaviour is not always observed, and internal motivations are hidden.

There has been a dramatic increase in the collection of movement data (Williams et al., 2020), owing to remote technologies such as global positioning systems (GPS; Hebblewhite \& Haydon, 2010; Seidel, Dougherty, Carlson, \& Getz, 2018). A challenge with these data is that behaviours accompanying movements are not typically recorded. Behavioural modes, therefore, must be inferred through statistical techniques (Patterson et al., 2017; Schick et al., 2008), such as change point analysis (Killick and Eckley 2014) or state space modelling (Patterson et al. 2008), that detect behavioural states in a time series of coordinates (Gurarie et al. 2016). However, the method for tracking butterflies, a model group for the study of movement and dispersal (Stevens, Trochet, Van Dyck, Clobert, \& Baguette, 2012; Stevens, Turlure, \& Baguette, 2010), is unusual, as movements have often been recorded by directly observing individuals over short timescales (Odendaal et al., 1989; Root \& Kareiva, 1984; Schultz, 1998; Schultz, Franco, \& Crone, 2012; Turchin, 1991). An advantage of this approach is that behaviours are recorded concurrently with movement data, and can be categorized simply (Dover, 1989), generating contemporaneous movement and behavioural information. This allows evaluation of the effect of observed behaviours on movement rates, rather than inferring behaviour from movement data. 
Previous studies have typically investigated movement modes in taxa larger and longer lived than insects. In the Artiodactyla, movements transition broadly between encamped and exploratory modes (Fryxell et al., 2008; Morales et al., 2004), further refined to bedding and foraging (Franke, Caelli, \& Hudson, 2004), predator avoidance (Forester et al., 2007) and seasonal migration (Singh et al., 2012). Similarly, for pinnipeds, movement modes have been identified for foraging at different depths (McClintock, London, Cameron, \& Boveng, 2017), in different seasons (Breed, Jonson, Myers, Bowen, \& Leonard, 2009), and for engaging in directed and undirected travel (Gurarie, Andrews, \& Laidre, 2009). For butterflies, changes in modes have often been associated with transitions between patches of varying habitat quality, where movement rates change in response to resource densities (Fownes \& Roland, 2002; Odendaal et al., 1989; Ovaskainen, Luoto, et al., 2008; Schtickzelle, Joiris, Dyck, \& Baguette, 2007). Less explored is how butterfly movements vary within contiguous habitats in response to motivation, and the consequences this has for movement rates and the fitness of individuals.

It has long been recognized that butterflies engage in behavioural modes targeted at specific purposes (Shreeve, 1992). Dennis and Hardy (2007) observed pierid species performing foraging or directed flight patterns in response to habitat quality, and studies using harmonic radar show butterflies engaging in distinct foraging or dispersive flights (Cant, Smith, Reynolds, \& Osborne, 2005). There is also much research on the sex-specific behaviours of butterflies (Scott, 1974; Wiklund, 2003). For example, Brakefield (1982a) noted meadow brown, Maniola jurtina, males engaging in patrolling behaviours, seeking out females on sustained flights. Similarly in other satyrids, males are known to switch between territorial and patrolling behaviours (Shreeve, 1984; Takeuchi, 2010; Wickman, 1985; Wiklund, 2003). Thus, butterflies appear to perform distinct modes related to specific goals and these may be consequential for understanding the movement of individuals and their distribution in an 
environment. Including behavioural variation in models of butterfly movement is known to affect predictions of movement rates (Evans et al., 2020b, 2020a); however, the way behavioural differences are implemented may influence predictions. In many random-walk or diffusion approaches individuals, at some level, are considered identical (Gurarie, Anderson, $\&$ Zabel, 2009); thus, within a given habitat, movement observations may be pooled (Evans et al., 2020b; Schultz \& Crone, 2001). However, other approaches maintain behavioural variation between individuals within the same habitat (Brown \& Crone, 2016; Korösi, Örvössy, Batáry, Kövér, \& Peregovits, 2008). Not well considered thus far is the effect of implementing behaviour through state switches, as has been applied in many other taxa (Morales et al., 2004; Patterson et al., 2017).

Here we aimed to explore butterfly movement behaviour through identifying and describing the behavioural modes of the model butterfly M. jurtina. To achieve this we utilized a large data set of both movement and behaviour, collected within areas of varying habitat quality (Evans, Sims, et al., 2019). Specifically, we aimed to (1) identify behavioural modes in the sexes and between habitats of varying resource density, (2) quantify the movement parameters associated with the modes, (3) demonstrate the consequences of behavioural modes for the distribution of individuals across a landscape using an individual-based random-walk model and (4) develop a model, from first principles, to explore the optimality of exclusive search modes for reproductive resources. We focused especially on the effect of behavioural modes in high-quality habitat as this is far less explored than the effects of habitat quality on movement.

\section{$<$ H1 > Methods}


$<H 2>$ Species

Maniola jurtina is a common butterfly found throughout the British Isles and much of Europe (Fox et al., 2015). It is a characteristic grassland specialist (Van Swaay et al., 2019), with larvae feeding on common grasses and herbs (Ouin, Martin, \& Burel, 2008) and the adults obtaining nectar from a variety of flowers (Brakefield, 1982a; Dennis, 1992; Lebeau, Wesselingh, \& Van Dyck, 2017). The species is univoltine and typically on the wing between June and September (Thomas 2010). The males emerge first (Brakefield, 1982b; Scali, 1971) and are more active flyers than the females, spending extra time in flight searching for receptive females (Brakefield, 1982a; Evans et al., 2020a; Evans, Sibly, et al., 2019a). The females are monandrous and typically mate quickly after emergence (Dowdeswell, 1981). When choosing host plants they are relatively unselective (Delattre et al., 2010), although they show preferences for short grasses (Lebeau, Wesselingh, \& Van Dyck, 2015). The adult life span in the British Isles is 5-12 days although can be as long as 20 days (Brakefield, 1982b), with survival duration probably reflecting the amount and quality of nectar resources (Evans, Sibly, et al., 2019b; Lebeau, Wesselingh, \& Van Dyck, 2016a).

\section{$<H 2>$ Movement and behavioural data}

An open-access data set of butterfly movement was analysed (Evans, Sims, et al., 2019) and as methods for this data collection are provided elsewhere we here provide only a brief description. Butterflies were followed opportunistically with movement and behaviour recorded simultaneously. Following a standard approach (Odendaal et al., 1989; Schultz, 1998; Turchin, 1991), movements were recorded by laying marker flags every time the butterfly alighted or every $15 \mathrm{~s}$ during continuous flight. Observations ceased after $10 \mathrm{~min}$ or after either 15 or 20 flags had been laid (15 flags in 2018 and 20 in 2017). The coordinates of 
the flags were then retroactively mapped using a high-grade global navigation satellite system receiver (Arrow 200 RTK GNSS, Eos Positioning Systems, Inc., Terrebonne, QC, Canada). During the observations, behaviours were recorded continuously by categorizing behaviour into flying, nectaring (taking nectar from flowers), basking (open wings and stationary), inactive (closed wing and stationary) or ovipositing (Dover 1989). Timing of behaviour was recorded accurately using a bespoke android phone app developed for the project.

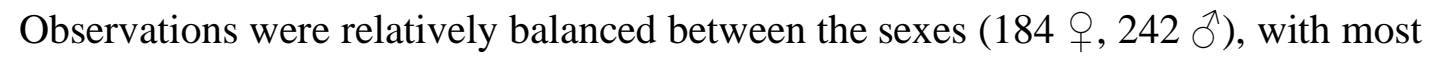
observations taking place in nectar-rich habitats (rich: 321 ; poor: 105). Data on individual flight tracks were collected over 72 days during the summers of 2016 (July-August), 2017 (June-September) and 2018 (June-July), at four sites in the south of England: North Farm in Oxfordshire $\left(51^{\circ} 37^{\prime} \mathrm{N}, 1^{\circ} 09^{\prime} \mathrm{W}\right)$, Jealott's Hill Farm, Berkshire $\left(51^{\circ} 27^{\prime} \mathrm{N}, 0^{\circ} 44^{\prime} \mathrm{W}\right)$, the University of Reading $\left(51.4414^{\circ} \mathrm{N}, 0.9418^{\circ} \mathrm{W}\right)$ and Sonning Farm, Berkshire $\left(51^{\circ} 28^{\prime} \mathrm{N}\right.$, $\left.0^{\circ} 53^{\prime} \mathrm{W}\right)$. Three of the sites were agricultural farms that had implemented agri-environment schemes and consisted of a mixture of arable fields, open meadows and nectar-rich field margins, while the fourth consisted of areas of meadow within the grounds of the University of Reading campus. Data were labelled dichotomously as either nectar rich or nectar poor, with nectar-rich areas consisting of grasslands with a variety of wildflowers while the nectarpoor sites were mowed grass with very few flowers. Hourly air temperature was collected from local meteorological stations and mean solar radiation during observations (recorded every $10 \mathrm{~s}$ ) from dataloggers (HOBO pendant, Tempcon Instrumentation, Arundel, U.K.).

\section{$<H 2>$ Ethical note}

Permissions were obtained from landowners for all sites visited during observations (The Earth Trust, Syngenta Jealotts Hill, the University of Reading, Sonning Farm University of 
Reading). All observations took place in the field and no butterflies were handled. The methods applied for observing butterfly movement have been demonstrated to have no observable impact on behaviour (Root \& Kareiva, 1984)

\section{$<H 2>$ Statistical analysis}

To identify behavioural modes, the analysis was conducted in two stages. First, data were collated into time budgets and a clustering approach was applied to group butterflies performing similar behaviours across an entire observation. This we consider as representative of a behavioural 'mode'. In this first stage, observations from both sexes and all habitat types were pooled and sex and habitat were used as predictors of cluster group identity in a multinomial regression. This first stage identified that, as expected, sex and habitat strongly predicted cluster grouping (see Results). Consequently, in the second stage, observations were split by sex and habitat type and a separate cluster analysis was performed to evaluate groupings in each sex*habitat combination. Identifying clusters in the nectar-poor habitat allowed us to compare responses to habitat quality with those found in the literature, although our analysis primarily focused on the modes of butterflies within nectar-rich habitats.

Silhouettes (Rousseeuw, 1987) were used to identify the number of clusters, ranking the proposed number by comparing the distances of objects contained within a cluster to the distance of the nearest neighbour of an adjacent cluster. Implementations are available in the R package 'cluster' (Maechler, Rousseeuw, Struyf, Hubert, \& Hornik, 2019). This provided an objective method to select the number of behavioural clusters in the data. With the number of cluster groupings selected, $K$-means clustering (Hartigan \& Wong, 1979) was applied. For comparisons in stage 1 , air temperature was introduced as a covariate, as insolation data were 
unavailable in nectar-poor regions. For stage 2, however, within the nectar-rich habitat, insolation was found to be a far superior predictor of clustering than air temperature (lower Akaike information criterion) and was used instead.

To compare step distances and turning angles between clusters within nectar-rich habitats, Tukey's test for comparing individual means was used for the step distances (Tukey, 1949). Wallraff rank sum tests of angular distance were used to compare differences in turning angles. Step distances were log transformed to meet the assumptions of Tukey's test.

Multinomial regression was carried out using the package 'nnet' (Ripley, Venables, \& Ripley, 2016), Silhouettes were produced using 'factoextra' (Kassambara \& Mundt, 2017), and Wallraff rank sum tests using 'circular' (Agostinelli \& Lund, 2017) all within R 3.6.1 (R Core Team, 2019).

\section{$<H 2>$ Random-walk models}

To explore the effect of behavioural modes on movement rates and the distribution of individuals, a simple individual-based random-walk model was developed. The model predicted the daily displacement from a fixed starting point after $8 \mathrm{~h}(28800 \mathrm{~s})$ of simulated time. Three versions were produced; all were sex specific but differed in their treatment of behaviour. The 'pooled' model simulated behaviour without reference to any behavioural variation; this we considered typical of random-walk or diffusion approaches where individuals are considered identical (Gurarie, Anderson, et al., 2009) and observations within a habitat type often pooled (Evans et al., 2020b; Schultz \& Crone, 2001). The 'mode' version was a state switch model (Morales et al., 2004; Patterson et al., 2017) that included transitions between modes and variation in step distances, turning angles and the proportion of time in flight for the behavioural modes. Finally, in the 'intraspecific' model, variation 
between individuals in movement propensity is seen as a fixed trait (Korösi et al., 2008) and the amount of time in flight matched the proportions observed. The models contain variation from different sources, the 'pooled' model from stochasticity in steps and turns, the 'mode' model additional stochasticity in choice of behavioural mode and the 'intraspecific' model fixed individual variation in flight propensity.

In the pooled model, butterflies moved by selecting steps and turning angles from all data in nectar-rich habitats. Movement occurred for a 'flight time' which was the mean of the observed proportion of time in flight multiplied by the total simulated time. For example, if butterflies spent on average $20 \%$ of their time in flight then total simulated flight time would be $0.2 \times 28800 \mathrm{~s}=5760 \mathrm{~s}$. For every step, the mean duration of the step distances was subtracted, and movement stopped when all butterflies had run out of flight time. For the mode model, butterflies selected behavioural modes in proportion to those observed in the switched every 10 min of simulated time, with the frequency of each mode proportional to that observed in the data. The flight time in each of the 10 min was the average proportion of time in flight for that cluster multiplied by $600 \mathrm{~s}$ and this was repeated until the total simulated time had elapsed. In the intraspecific model, butterflies drew the proportion of time in flight from observations but moved using pooled steps and turning angles. The pooling at this stage was used because not all butterflies had sufficient steps to generate appropriate individual turning angle and step distributions.

To compare the models, for each sex and model type combination, 5000 butterflies were initialized at the centre of a $2 \times 2 \mathrm{~km}$ landscape and the model was run for the simulated day.

246 The landscape was made sufficiently large to avoid any edge effects. At the end of the run 247 Euclidean distance from the start location for each butterfly was then recorded, thus 
representing the total displacement and the change in the distribution of the butterflies in the habitat.

250 The model was built in NetLogoR (Bauduin, McIntire, \& Chubaty, 2019), a recently

251 developed set of individual-based functions inspired by the NetLogo language which can be

252

253

254

255

256

257 used for developing individual-based models within R (code is available at DOI: 10.17632/mm2skm8f6j.1). Turning angles were simulated used the 'circular' package (Agostinelli \& Lund, 2017).

$<\mathrm{H} 2>$ Exclusive search model

A model was derived from first principles to explore the utility of searching behavioural modes for both sexes. The model conceptualized a trade-off between exclusively searching for the resources associated with reproductive fitness (e.g. host plants, receptive females) and finding these resources as a by-product of normal, lower net-energy expenditure, behaviours of foraging and inactivity. Specifically, the model aimed to explore how much time individuals should dedicate to an exclusive search mode given (1) the change in resource over time, (2) the energetic cost of search behaviour and (3) the relative effectiveness of exclusive search over normal behaviours. It is assumed that when in exclusive search mode butterflies trade life span for resources by consuming no nectar and thus use reserves, resulting in reduced life span (Evans, Sibly, et al., 2019b; Lebeau et al., 2016a; Vande Velde \& Van Dyck, 2013). It is also assumed that butterflies can maintain net energy balance in inactive/foraging modes by replenishing expended energy with nectar sugar and becoming inactive to reduce metabolic rate (Lebeau, Wesselingh, \& Van Dyck, 2016b; Niitepold, 2010; Niven \& Scharlemann, 2005). Thus, lifetime energy use can be represented as:

$$
L_{e}=E_{s} T_{s}
$$

where $L_{e}=$ lifetime net energy use, $E_{s}=$ energetic cost of $\operatorname{search}(\mathrm{J} / \mathrm{s}), T_{\mathrm{s}}=$ time in search $(\mathrm{s})$ 
272

273

274

276

277

278

280

281

282

283

284

285

286

287

288

289

290

291

292

293

This can be converted to a reduction in survival time by multiplying by a factor, $A$, that relates energy loss to survival time. Combining $E_{s}$ and $A$ creates variable $A^{\prime}$ and the equation for predicting life span is:

$$
\mathrm{LS}=\mathrm{LS}_{n}-A^{\prime} T_{S}
$$

where $\mathrm{LS}=$ life span (s) and $\mathrm{LS}_{n}=$ maximal life span (s).

Dividing this equation by the maximal life span generalizes the equation to different maximal life spans and transforms times in modes into proportions of life span

$$
\mathrm{LS}_{p}=1-A^{\prime} T_{s p}
$$

where $\mathrm{LS}_{p}=$ life span, $T_{s p}=$ proportion of life span spent in search. Now $A^{\prime}$ is the amount by which life span is reduced when the adult butterfly takes in no nectar.

Next, the proportional number of resources discovered during a lifetime is the sum of the relative success of the two modes multiplied by the number of resources. First, the approximate number of resources located is represented as

$$
\text { Area } \sim\left(1-T_{s p}\right)+\left(T_{s p} B\right)
$$

where Area $=$ the area searched and $B=$ the relative efficiency of search, or similarly stated, the relative amount of area covered by exclusive search compared to nonexclusive search.

Resources are assumed to be uniformly spaced and so the number of resources located is the product of the area searched (Area) and the density of resources. For replicating finite resources, resources change through time using a linear function and so the density of resources across a lifetime is the integral of the resource amount function multiplied by equation (2). As either death of the butterfly or the total extinguishing of resources may come first then the equations given below follow: 


$$
\mathrm{LS}_{p}<\frac{1}{c} \rightarrow \int_{0}^{\mathrm{LS}}{ }_{p} 1-c t d t=\mathrm{LS}_{p}-c \frac{\mathrm{LS}_{p}^{2}}{2}
$$

$$
\frac{1}{c}<\mathrm{LS}_{p} \rightarrow \int_{0}^{\frac{1}{c}} 1-c t d t=\frac{1}{c}-\frac{1}{2 c}
$$

296

297

298

299

300

301

302

303

304

305

306

307

308

309

310

311

312

313

where $c=$ the rate of diminishment of resources over time and $1 / \mathrm{c}$ the point at which resource densities are 0 .

Multiplying (3a) and (3b) by (2) produces equations for the relative number of resources, $N_{\text {items, }}$ located during a lifetime, which can be evaluated in response to $A^{\prime}, B$ and $c$, the cost of exclusive search, its relative effectiveness and the rate of resource diminishment, respectively.

$$
\left.\mathrm{LS}_{p}<\frac{1}{c} \rightarrow N_{\text {items }}=1-A^{\prime} T_{s p}-c \frac{\left(1-A^{\prime} T_{s p}\right)^{2}}{2}\left(\left(1-T_{s p}\right)+T_{s p} B\right)\right)
$$

$$
\left.\frac{1}{c}<\mathrm{LS}_{p} \rightarrow N_{\text {items }}=\left(\frac{1}{c}-\frac{1}{2 c}\right)\left(\left(1-T_{s p}\right)+T_{s p} B\right)\right)
$$

For the analysis $A^{\prime}$ was estimated at 0.5 for $M$. jurtina, predicting a loss of $50 \%$ of life span when consuming no resources (Evans, Sibly, et al., 2019b; Lebeau et al., 2016a; Vande Velde $\&$ Van Dyck, 2013). The effects of variables $B$ and $c$ were then evaluated to determine how much exclusive search individuals should undertake to maximize the number of resources encountered. Presented results include evaluating $T_{s p}$ after conditioning on $c$ for values of 0 and 1 , relating to conditions where resources do not diminish (females locating host plants), and when resources are at 0 at $100 \%$ of total life span (assuming male life span is adapted to available reproductive opportunities).

\section{$<$ H1 $>$ Results}

$<H 2>$ Cluster analysis across habitat types and sexes 
Four clusters were selected by silhouettes of the time budget data, and $K$-means clustering individual being included in a particular cluster grouping was strongly predicted by sex and habitat type (Table 1). Clusters consisted of four main groupings: (1) a combination of basking, inactivity and flying that was shared in equal proportions between the sexes; (2) large amounts of time in flight, the majority male, and located predominantly in nectar-poor habitats; (3) inactivity, which was mainly female and split equally between habitat types; and (4) nectaring, containing a higher proportion of females and found exclusively in nectar-rich habitats. For convenience, we use the descriptive labels 'high-bask', 'high-flight', 'highinactive' and 'high-nectar', respectively.

Males had an increased probability of classification in the 'high-flight' cluster and a reduced probability of classification in the 'high-nectar' cluster compared to females. In nectar-rich habitats, 'high-flight' was reduced relative to 'high-inactive', meaning 'high-flight' was more likely in nectar-poor habitats. The probability of being grouped into 'high-bask' also increased in nectar-rich habitats. In contrast, there was no significant effect of habitat on the probability of classification of 'high-nectar' relative to 'high-inactive'. This may appear counterintuitive, but it is due to the baseline condition of 'high-inactive' being common in nectar-rich patches (Fig. 1).

\section{$<H 2>$ Clusters within sexes and habitat types}

When data were split by sex and habitat, different clusters were identified, with three groups for females in nectar-rich habitat: (1) 'high-nectar'; (2) 'high-inactive'; and (3) 'high-bask' a group that also contained inactivity, flying and oviposition. Male behaviour was more diversified with five groups identified: (4) 'high-flight'; (5) 'high-nectar'; (6) 'high-inactive'; 
339

(7) 'high-bask' a group similar to that identified in females that contained basking and small amounts of the other behaviours; and (8) an additional group containing a majority of switches between inactivity and flight, termed here 'mixture'. Males and females had similar behavioural groupings in nectar-poor habitats, consisting of either 'high-flight' or 'highinactivity'. For both sexes in nectar-rich habitats, insolation strongly influenced cluster allocation (Table 2). In nectar-poor habitat, behaviour for both sexes was less diverse with only two cluster groupings identified corresponding with a 'high-flight' and 'high-inactive' group.

\section{$<H 2>$ Movement behaviour in sex-specific clusters}

In nectar-rich habitats, step distances were found to differ between the clusters for both males $\left(F_{4}=7.86, P<0.001\right)$ and females $\left(F_{2}=4.97, P<0.001\right)$. For males, Tukey's test showed differences mostly between 'high-nectar' and the other groups ('high-inactive', 'mixed' and 'high-flight') with steps shorter for 'high-nectar' (Fig. 2a). 'High-flight' and 'mixed' were also significantly different. Males' turning angles varied between 'high-nectar' and all other groups, with turning angles more tortuous in 'high-nectar' (Fig. 2b). There were also differences between 'high-flight' and 'high-bask', and 'high-bask' and 'mixed' (full results Table S3 and S4). For females, step distances were only significantly different between 'high-nectar' and 'high-inactive' (Fig. 2c). There were also differences in turning angle between 'high-nectar' and all other groups (Fig. 2d).

\section{$<H 2>$ Consequences of behaviour modes for movement rates}

The individual-based random-walk model was used to evaluate the effect of implementation of behavioural differences on predicted movement rates within nectar-rich habitats. For both 
males and females, the inclusion of modes and intraspecific variation had a large effect on the mean and shape of the resultant displacement distribution (Fig. 3). Overall, the mode and intraspecific models produced longer-tailed distributions than the pooled model, although the models differed between the sexes. For males, the mean displacement of the mode model was lowest $(201 \pm 1 \mathrm{~m})$ followed by the intraspecific $(239 \pm 3 \mathrm{~m})$ and then the pooled model (302 $\pm 1 \mathrm{~m}$; Fig. 3a). However, the reverse was the case for the females where the mode model had the largest mean displacement $(106 \pm 1 \mathrm{~m})$, the intraspecific model was intermediate $(101 \pm 2$ m) and the pooled model the lowest ( $70 \pm 1 \mathrm{~m}$; Fig. $3 \mathrm{~b})$.

\section{$<H 2>$ Modelling optimal time in exclusive search}

The optimal amount of time in exclusive search mode $\left(T_{s p}\right)$ is shown against the efficiency of exclusive search $(B)$ and the rate of resource diminishment $(c)$ in Fig. 4a. In general, when efficiency is low and resources only slowly diminish, butterflies should spend little or no time in exclusive search and should locate sex-specific resources as a by-product of behaviour that maximizes survival. However, if resources diminish very quickly and exclusive search is efficient, butterflies should spend all their time in exclusive search with a subsequent sacrifice of life span. With no resource diminishment (Fig. 4b), a case likely to be representative of $M$. jurtina which feeds on common grasses, females should only spend time in exclusive search when its efficiency is 1.5 times that of survival/foraging behaviour. With a higher rate of resource diminishment (Fig. 4c), a case representative of male M. jurtina locating receptive females in this monandrous species, butterflies should always spend some time in exclusive search even if it is only marginally more efficient than normal behaviour, increasing up to more than $75 \%$ when search is twice as efficient. 


\section{$<$ H1 $>$ Discussion}

389

390

391

392

393

394

395

396

397

398

399

400

401

402

403

404

405

406

407

408

409

410

In this study, we explored various aspects of the behavioural modes of the model butterfly $M$. jurtina. In nectar-poor regions, both sexes were characterized by modes of either inactivity or high amounts of time in flight. In nectar-rich habitats, however, sex-specific behaviour was more diversified. Females had three modes, 'high inactivity', 'high-basking' and 'highnectar', and males additionally had 'high-flight' and 'mixed' modes consisting of a high proportion of time in flight, and transitions between flight and inactivity. Movement parameters differed between the modes (Fig. 2) and their inclusion in a random-walk model had large effects on the shape of the displacement distribution (Fig. 3). Including modes also had different effects on the spatial distribution of the sexes, with males moving less on average compared to the other model versions while for females including modes increased movement. Finally, the model of exclusive search behaviour demonstrated the general conditions under which exclusive search is favoured (Fig. 4) and indicated the time that should be spent in exclusive search given its cost, its effectiveness and the rate of resource diminishment.

In nectar-poor regions, behavioural modes were similar for the sexes, and consisted of either inactivity or spending a high proportion of their time in flight. As these areas have low resource densities, a parsimonious explanation for these modes is that flight and inactivity are the only possibilities, thus requiring no account of motivation. However, as increasing movement rate in response to poor-quality habitats is common to many butterfly species (Fownes \& Roland, 2002; Odendaal et al., 1989; Ovaskainen, Rekola, Meyke, \& Arjas, 2008; Roland, Keyghobadi, \& Fownes, 2000; Schtickzelle et al., 2007; Zalucki \& Kitching, 1982), and is a general response across many taxa (Fryxell et al., 2008; Haskell, 1997; Smith, 1974; 
Zollner \& Lima, 2005), the 'high-flight' mode observed is likely to be a specific behaviour

412 pattern aimed at quickly moving $M$. jurtina out of poor-quality areas and not only a by-

413 product of low resource density. That movement in these areas is also faster and straighter

414 (Evans et al., 2020b) suggests that a 'high-flight' mode may correspond with exploratory or

415 dispersive movement (Delattre et al., 2010), as seen in many other taxa (Patterson, Thomas,

416 Wilcox, Ovaskainen, \& Matthiopoulos, 2008) and is probably distinct from behaviour

417 occurring in nectar-rich habitats. This is most notable in the females where, in nectar-rich

418 habitats, the 'high-flight' mode was absent. Therefore, it seems likely that butterflies in

419 poorer-quality regions are either unable to fly due to thermal or physiological constraints, or

420 switching to flying frequently.

421 In nectar-rich habitats, males and females had different modes that largely corresponded with

422 previous work evaluating sex-specific behaviour in butterflies (Brakefield, 1982a; Scott,

423 1974; Shreeve, 1992; Wiklund, 2003). Females were either inactive, basking or nectaring.

424 This low-energy regime corresponds with maximizing adult life span which, from the

425 exclusive search model, is an optimal strategy. Females of $M$. jurtina progressively mature

426 eggs through their life span (Scali, 1971), probably producing a strong correspondence

427 between fitness and survival time. Oviposition was seen in the 'high-bask' cluster, although

428 still observed rarely. Therefore, it was not possible to determine a distinct oviposition mode.

429 Females of $M$. jurtina have a flight pattern that does correspond with oviposition, flying low

430 over the ground and laying a series of single eggs each a short distance apart, although this

431 was indistinct from other behavioural modes probably because of the timescale of our

432 observations. Males had two additional behaviours, 'high-flight' and 'mixed'. 'High-flight'

433 we consider to correspond with a behaviour termed patrolling (Brakefield, 1982a) where

434 males fly for longer periods as they search for receptive females and engage less in 
optimal strategy for maximizing the number of receptive females located, incentivizing some sacrifice of life span. The other mode termed 'mixed' may relate to perching behaviour seen in the grassland species Coenonympha pamphilus (Wickman, 1985) and Lasiommata megera (Dennis, 1982), the woodland species Pararge aegeria (Bergman et al., 2007; Shreeve, 1984; Wiklund, 2003) and also possibly M. jurtina (Brakefield, 1982a). This is an alternative matefinding strategy where males wait inactive and chase females as they pass by. However, it is also possible that, as butterflies were followed opportunistically, the 'mixed' mode consisted of transitions between the other modes, rather than a specific behavioural pattern; therefore, we limit our interpretation at this time.

For both sexes, movement parameters were found to differ largely between 'high-nectar' and the other modes, although 'high-flight' also differed for males (Fig. 2). The short step distances and tortuosity of 'high-nectar' are probably a by-product of moving from flower to flower and slower flight speeds may relate to the ability to survey potential resources in flight (Chittka, Dyer, Bock, \& Dornhaus, 2003; Chittka, Skorupski, \& Raine, 2009). 'High-flight' also probably results in longer step distances and straighter flight paths as males attempt to survey larger areas when searching for females. The variation in the movement parameters and the effect of implementing behaviour in the individual-based random-walk model combined to have large effects on displacement distributions (Fig. 3). The relationship of the mode model to the intraspecific and pooled models was qualitatively different between the sexes. We attribute this to the mode model replicating transition through behavioural states, generating females that move more than was observed individually (intraspecific model), while also switching between the more and less diffusive movement states absent in the pooled model. For males, the mode model was intermediate between the intraspecific model, where observed individual differences are extrapolated, to the pooled model where individuals are identical. Disentangling the effects of intraspecific variation versus 
behavioural modes is challenging. Models that incorporate intraspecific variation in movement rate have been successful in replicating realistic movement patterns (Brown \& that traits such as metabolic rate consistently influence interindividual variation in movement (Mattila, 2015; Ovaskainen, Smith, et al., 2008). Consequently, both movement modes and syndromes (Sih, Bell, \& Johnson, 2004; Spiegel, Leu, Bull, \& Sih, 2017) are likely to be important for understanding species movement rates. We suggest though, that for short timescale observations (tens of minutes), such as those for butterflies, it may be challenging to separate movement modes from individual propensities and their effect on movement predictions needs careful consideration.

The exclusive search model provides the general conditions (Fig. 4) under which exclusive search is favoured. In two examples, we considered nondiminishing and diminishing resources, representing female $M$. jurtina searching for host plants and males searching for receptive females. For females, exclusive search was only advantageous when it was more than 1.5 times more successful for locating host plants than normal behaviour. As grasses are relatively ubiquitous, females of $M$. jurtina can be predicted to have little exclusive search behaviour and no specific mode for host plant search was in evidence. Similarly, as females are monandrous, we expected males to engage in exclusive search and we found evidence of patrolling behaviour. Generally, the amount of exclusive search could relate not only to properties of flight paths but also to the distribution of resources. For example, pierid species lay eggs on brassicas (Thomas, 2010) which are rarer and more clumped than grasses, probably requiring an exclusive search for locating plants, and female pierids engage in active search for host plants (Dennis \& Hardy, 2007; Root \& Kareiva, 1984). Likewise, in polygamous species, or those with active females, we may assume less necessity for the males to engage in exclusive search. Thus the model provides a framework to view the sex- 
specific behaviour of many butterfly species from estimated parameters such as the cost of search (widely available e.g. Lebeau et al., 2016b; Niitepõld \& Boggs, 2015; Woods, Wood, Ebersole, \& Stevenson, 2010), the effectiveness of search and the rate of resource diminishment. Some factors are not taken into account by the model, such as the effect of different tactics used by perching or lekking butterflies (Alcock, 1985; Brown \& Alcock, 1990; Scott, 1974), which would strongly influence both the success and the cost of search (Dennis \& Shreeve, 1988), although the model could be adapted through the appropriate parameterization. Further, the assumption of uniform resources over the landscape is simplistic, and it would be useful to evaluate how changes in the efficiency of search over time might influence the use of exclusive search.

A limitation of this study is that the description of modes is related to the duration of observations, risking the methods influencing our interpretation of the results. We feel here though that the ability to group behaviour into meaningful clusters that correspond with previous observations of butterfly behaviours demonstrates timescales at tens of minutes are appropriate. Further, an ability to separate intraspecific variation from behavioural modes would be enhanced by following butterflies for longer periods and attempting to observe switches between modes within individuals. This is feasible, but due to the intensive nature of the data collection would be time consuming to accumulate for a large sample of individuals. Finally, the main focus of the study was behaviour operating within nectar-rich habitats, and extrapolating movement to complex habitats will require a better understanding of how modes change in response to habitat types, varying resource densities, habitat edges and an individual's age and condition (Conradt, Bodsworth, Roper, \& Thomas, 2000; Conradt \& Roper, 2006; Delattre et al., 2010; Kallioniemi, Zannese, Tinker, \& Franco, 2014; Mair, Thomas, Franco, \& Hill, 2015; Polic, Fiedler, Nell, \& Grill, 2014; Schneider, 2003). These other factors may be particularly important for sedentary species like M. jurtina for which 
mark-recapture studies find lower mean dispersal estimates (45-414 m; Schneider, Dover, \&

512 Fry, 2003) than would be expected from direct extrapolations of movement observations.

513 In conclusion, we have identified the importance of behavioural modes for the fitness and

514 movement behaviour of the model species M. jurtina. Our results provide two main innovations. First, we evaluated, in a movement model, the effect of behavioural modes on predicted movement rates. Second, we produced a search model that conceptualized the trade-off between searching for the resources necessary for reproductive fitness and searching for those for sustaining life span. The balance between reproduction and survival is central to the life history of all species and we hope that our search model, targeted at understanding this trade-off in M. jurtina, will provide a useful route to evaluating how butterflies and other species maximize their fitness given the resources they utilize and the constraints acting on their mobility and perception. Our movement model demonstrated that the different methods of incorporating interindividual variability have large effects on movement predictions. In particular, we identified the challenge of disentangling intraspecific variation from contextspecific behavioural modes. Further work attempting to evaluate butterfly movement in light of these concepts is likely to allow better integration of the wealth of behavioural information on butterflies when investigating aspects of their movement ecology such as habitat use, optimal foraging and dispersal.

\section{Acknowledgments}

531 L.C.E was supported by a Biotechnology and Biological Sciences Research Council

CASE/Syngenta PhD studentship award (Grant number BB/N504129/1). Access to sites was 
534

535

536

537

538

539

540

541

542

543

544

545

546

547

548

549

550

551

552

553

554

555

grateful to additional research assistance in the field provided by undergraduate students

Andrew Tarbie and Ginny Crouch.

\section{References}

Agostinelli, C., \& Lund, U. (2017). R package 'circular': Circular statistics (version 0.4-93). R Package. Retrieved from https://r-forge.r-project.org/projects/circular/

Alcock, J. (1985). Hilltopping in the nymphalid butterfly Chlosyne californica (Lepidoptera). American Midland Naturalist, 113, 69-75.

Alexander, R. M. (2003). Principles of animal locomotion. Princeton University Press.

Avgar, T., Kuefler, D., \& Fryxell, J. M. (2011). Linking Rates of Diffusion and Consumption in Relation to Resources. The American Naturalist, 178(2), 182-190. https://doi.org/10.1086/660825

Bauduin, S., McIntire, E. J. B., \& Chubaty, A. M. (2019). NetLogoR: a package to build and run spatially explicit agent-based models in R. Ecography, 42(11), 1841-1849. https://doi.org/10.1111/ecog.04516

Bergman, M., Gotthard, K., Berger, D., Olofsson, M., Kemp, D. J., \& Wiklund, C. (2007). Mating success of resident versus non-resident males in a territorial butterfly. Proceedings of the Royal Society B: Biological Sciences, 274(1618), 1659-1665. https://doi.org/10.1098/rspb.2007.0311

Börger, L., Dalziel, B. D., \& Fryxell, J. M. (2008). Are there general mechanisms of animal home range behaviour? A review and prospects for future research. Ecology Letters, 11(6), 637-650. https://doi.org/10.1111/j.1461-0248.2008.01182.x 
Brakefield, P. M. (1982a). Ecological Studies on the Butterfly Maniola jurtina in Britain. I. Adult Behaviour, Microdistribution and Dispersal. Journal of Animal Ecology, 51(3), 713. https://doi.org/10.2307/4000

Brakefield, P. M. (1982b). Ecological Studies on the Butterfly Maniola jurtina in Britain. II. Population Dynamics: The Present Position. Journal of Animal Ecology, 51(3), 727. https://doi.org/10.2307/4001

Breed, G. A., Jonson, I. D., Myers, R. A., Bowen, W. D., \& Leonard, M. L. (2009). Sexspecific, seasonal foraging tactics in adult gray seals (Halichoerus grypus) are revealed by behaviour discriminating state-space models. Ecology, 90(11), 3209-3221.

Brown, L. M., \& Crone, E. E. (2016). Individual variation changes dispersal distance and area requirements of a checkerspot butterfly. Ecology, 97(1), 106-115. https://doi.org/10.1002/ecy.1216

Brown, W. D., \& Alcock, J. (1990). Hilltopping by the red admiral butterfly: Mate searching alongside congeners. Journal of Research on the Lepidoptera, 29(1), 1-10.

Cant, E., Smith, A., Reynolds, D., \& Osborne, J. (2005). Tracking butterfly flight paths across the landscape with harmonic radar. Proceedings of the Royal Society B: Biological Sciences, 272(1565), 785-790. https://doi.org/10.1098/rspb.2004.3002

Charnov, E. L. (1976). Optimal foraging, the marginal value theorem. Theoretical Population Biology, 9(2), 129-136. https://doi.org/10.1016/0040-5809(76)90040-X

Chittka, L., Dyer, A. G., Bock, F., \& Dornhaus, A. (2003). Bees trade off foraging speed for accuracy. Nature, 424(6947), 388-388. https://doi.org/10.1038/424388a

Chittka, L., Skorupski, P., \& Raine, N. E. (2009). Speed-accuracy tradeoffs in animal decision making. Trends in Ecology \& Evolution, 24(7), 400-407. 
Conradt, L., Bodsworth, E. J., Roper, T. J., \& Thomas, C. D. (2000). Non-random dispersal in the butterfly Maniola jurtina : implications for metapopulation models. Proceedings of the Royal Society of London. Series B: Biological Sciences, 267(1452), 1505-1510. https://doi.org/10.1098/rspb.2000.1171

Conradt, L., \& Roper, T. J. (2006). Nonrandom movement behavior at habitat boundaries in two butterfly species: Implications for dispersal. Ecology, 87(1), 125-132. https://doi.org/10.1890/05-0413

Delattre, T., Burel, F., Humeau, A., Stevens, V. M., Vernon, P., \& Baguette, M. (2010). Dispersal mood revealed by shifts from routine to direct flights in the meadow brown butterfly Maniola jurtina. Oikos, 119(12), 1900-1908. https://doi.org/10.1111/j.16000706.2010.18615.x

Dennis, R. L. H. (1982). Mate location strategies in the wall brown butterfly, Lasiommata megera (L.) (Lepidoptera: Satyridae): wait or seek? Entomologist's Record and Journal of Variation, 94, 209-214.

Dennis, R. L. H. (1992). Ecology of butterflies in Britain. Oxford University Press.

Dennis, R. L. H., \& Hardy, P. B. (2007). Support for mending the matrix: resource seeking by butterflies in apparent non-resource zones. Journal of Insect Conservation, 11(2), 157-168. https://doi.org/10.1007/s10841-006-9032-y

Dennis, R. L. H., \& Shreeve, T. G. (1988). Hostplant-habitat structure and the evolution of butterfly mate-locating behaviour. Zoological Journal of the Linnean Society, 94(4), $301-318$.

Dias, M. P., Granadeiro, J. P., \& Palmeirim, J. M. (2009). Searching behaviour of foraging waders: does feeding success influence their walking? Animal Behaviour, 77(5), 1203- 
603

604

605

606

607

608

609

610

611

612

613

614

615

616

617

618

619

620

621

622

623

624

Dover, J. W. (1989). A method for recording and transcribing observations of butterfly behaviour. Entomologist's Gazette, 40, 95-100.

Dowdeswell, W. (1981). The life of the meadow brown. Butler \& Tanner.

Evans, L. C., Sibly, R. M., Thorbek, P., Sims, I., Oliver, T. H., \& Walters, R. J. (2019a). Integrating the influence of weather into mechanistic models of butterfly movement. Movement Ecology, 7(1), 24. https://doi.org/10.1186/s40462-019-0171-7

Evans, L. C., Sibly, R. M., Thorbek, P., Sims, I., Oliver, T. H., \& Walters, R. J. (2019b). Quantifying the effectiveness of agri-environment schemes for a grassland butterfly using individual-based models. Ecological Modelling, 411, 108798. https://doi.org/10.1016/j.ecolmodel.2019.108798

Evans, L. C., Sibly, R. M., Thorbek, P., Sims, I., Oliver, T. H., \& Walters, R. J. (2020a). Behavior underpins the predictive power of a trait-based model of butterfly movement. Ecology and Evolution, 10(7), 3200-3208. https://doi.org/10.1002/ece3.5957

Evans, L. C., Sibly, R. M., Thorbek, P., Sims, I., Oliver, T. H., \& Walters, R. J. (2020b). The importance of including habitat-specific behaviour in models of butterfly movement. Oecologia, (0123456789). https://doi.org/10.1007/s00442-020-04638-4

Evans, L. C., Sims, I., Sibly, R. M., Thorbek, P., Oliver, T. H., \& Walters, R. J. (2019). Data on the movement behaviour of four species of grassland butterfly. Data in Brief, 27, 104611. https://doi.org/10.1016/j.dib.2019.104611

Forester, J. D., Ives, A. R., Turner, M. G., Anderson, D. P., Fortin, D., Beyer, H. L., ... Boyce, M. S. (2007). State-space models link elk movement patterns to landscape characteristics in Yellowstone national park. Ecological Monographs, 77(2), 285-299. 
626

627

628

629

630

631

632

633

634

635

636

637

638

639

640

641

642

643

644

645

646

647

Fownes, S., \& Roland, J. (2002). Effects of meadow suitability on female behaviour in the alpine butterfly Parnassius smintheus. Ecological Entomology, 27(4), 457-466. https://doi.org/10.1046/j.1365-2311.2002.00426.x

Fox, R., Brereton, T. M., Asher, J., August, T. A., Botham, M. S., Bourn, N. A. D., ... Harrower, C. A. (2015). The state of the UK's butterflies 2015. Butterfly Conservation/Centre for Ecology and Hydrology.

Franke, A., Caelli, T., \& Hudson, R. J. (2004). Analysis of movements and behavior of caribou (Rangifer tarandus) using hidden Markov models. Ecological Modelling, 173(2-3), 259-270. https://doi.org/10.1016/j.ecolmodel.2003.06.004

Fryxell, J. M., Hazell, M., Borger, L., Dalziel, B. D., Haydon, D. T., Morales, J. M., ... Rosatte, R. C. (2008). Multiple movement modes by large herbivores at multiple spatiotemporal scales. Proceedings of the National Academy of Sciences, 105(49), 19114-19119. https://doi.org/10.1073/pnas.0801737105

Gurarie, E., Anderson, J. J., \& Zabel, R. W. (2009). Continuous models of population-level heterogeneity inform analysis of animal dispersal and migration. Ecology, 90(8), 22332242. https://doi.org/10.1890/08-0359.1

Gurarie, E., Andrews, R. D., \& Laidre, K. L. (2009). A novel method for identifying behavioural changes in animal movement data. Ecology Letters, 12(5), 395-408. https://doi.org/10.1111/j.1461-0248.2009.01293.x

Hartigan, J. A., \& Wong, M. A. (1979). Algorithm AS 136: A K-Means Clustering Algorithm. Applied Statistics, 28(1), 100. https://doi.org/10.2307/2346830

Haskell, D. G. (1997). Experiments and a model examining learning in the area-restricted 

search behavior of ferrets (Mustela putorius furo). Behavioral Ecology, 8(4), 448-449. https://doi.org/10.1093/beheco/8.4.448

Hebblewhite, M., \& Haydon, D. T. (2010). Distinguishing technology from biology: a critical review of the use of GPS telemetry data in ecology. Philosophical Transactions of the Royal Society B: Biological Sciences, 365(1550), 2303-2312.

Holyoak, M., Casagrandi, R., Nathan, R., Revilla, E., \& Spiegel, O. (2008). Trends and missing parts in the study of movement ecology. Proceedings of the National Academy of Sciences, 105(49), 19060-19065. https://doi.org/10.1073/pnas.0800483105

Jonsen, I. D., Myers, R. A., \& James, M. C. (2006). Robust hierarchical state-space models reveal diel variation in travel rates of migrating leatherback turtles. Journal of Animal Ecology, 75(5), 1046-1057. https://doi.org/10.1111/j.1365-2656.2006.01129.x

Kallioniemi, E., Zannese, A., Tinker, J. E., \& Franco, A. M. A. (2014). Inter- and intraspecific differences in butterfly behaviour at boundaries. Insect Conservation and Diversity, 7(3), 232-240. https://doi.org/10.1111/icad.12046

Kassambara, A., \& Mundt, F. (2017). Factoextra: extract and visualize the results of multivariate data analyses. R Package Version 1.0.5. Retrieved from https://cran.rproject.org/web/packages/factoextra/factoextra.pdf

Korösi, Á., Örvössy, N., Batáry, P., Kövér, S., \& Peregovits, L. (2008). Restricted withinhabitat movement and time-constrained egg laying of female Maculinea rebeli butterflies. Oecologia, 156(2), 455-464. https://doi.org/10.1007/s00442-008-0986-1

Lebeau, J., Wesselingh, R. A., \& Van Dyck, H. (2015). Butterfly Density and Behaviour in Uncut Hay Meadow Strips: Behavioural Ecological Consequences of an AgriEnvironmental Scheme. PLoS One, 10(8), e0134945. 
672

673

674

675

676

677

678

679

680

681

682

683

684

685

686

687

688

689

690

691

692

693

Lebeau, J., Wesselingh, R. A., \& Van Dyck, H. (2016a). Floral resource limitation severely reduces butterfly survival, condition and flight activity in simplified agricultural landscapes. Oecologia, 180(2), 421-427. https://doi.org/10.1007/s00442-015-3492-2

Lebeau, J., Wesselingh, R. A., \& Van Dyck, H. (2016b). Nectar resource limitation affects butterfly flight performance and metabolism differently in intensive and extensive agricultural landscapes. Proceedings of the Royal Society B: Biological Sciences, 283(1830), 20160455. https://doi.org/10.1098/rspb.2016.0455

Lebeau, J., Wesselingh, R. A., \& Van Dyck, H. (2017). Flower use of the butterfly Maniola jurtina in nectar-rich and nectar-poor grasslands: a nectar generalist with a strong preference? Insect Conservation and Diversity, 10(3), 258-270. https://doi.org/10.1111/icad.12222

Louzao, M., Wiegand, T., Bartumeus, F., \& Weimerskirch, H. (2014). Coupling instantaneous energy-budget models and behavioural mode analysis to estimate optimal foraging strategy: an example with wandering albatrosses. Movement Ecology, 2(1), 8. https://doi.org/10.1186/2051-3933-2-8

Maechler, M., Rousseeuw, P., Struyf, A., Hubert, M., \& Hornik, K. (2019). cluster: Cluster Analysis Basics and Extensions. R Package Version 2.1.0. Retrieved from https://cran.rproject.org/web/packages/cluster/cluster.pdf

Mair, L., Thomas, C. D., Franco, A. M. A., \& Hill, J. K. (2015). Quantifying the activity levels and behavioural responses of butterfly species to habitat boundaries. Ecological Entomology, 40(6), 823-828. https://doi.org/10.1111/een.12248

Mattila, A. L. K. (2015). Thermal biology of flight in a butterfly: genotype, flight 
694

695

696

697

698

699

700

701

702

703

704

705

706

707

708

709

710

711

712

713

714

715

716

metabolism, and environmental conditions. Ecology and Evolution, 5(23), 5539-5551. https://doi.org/10.1002/ece3.1758

McClintock, B. T., London, J. M., Cameron, M. F., \& Boveng, P. L. (2017). Bridging the gaps in animal movement: hidden behaviors and ecological relationships revealed by integrated data streams. Ecosphere, 8(3), e01751. https://doi.org/10.1002/ecs2.1751

Morales, J. M., \& Ellner, S. P. (2002). Scaling up animal movements in heterogeneous landscapes: the importance of behavior. Ecology, 83(8), 2240-2247.

Morales, J. M., Haydon, D. T., Frair, J., Holsinger, K. E., \& Fryxell, J. M. (2004). Extracting more out of relocation data: building movement models as mixtures of random walks. Ecology, 85(9), 2436-2445. https://doi.org/10.1890/03-0269

Nathan, R., Getz, W. M., Revilla, E., Holyoak, M., Kadmon, R., Saltz, D., \& Smouse, P. E. (2008). A movement ecology paradigm for unifying organismal movement research. Proceedings of the National Academy of Sciences, 105(49), 19052-19059. https://doi.org/10.1073/pnas.0800375105

Niitepold, K. (2010). Genotype by temperature interactions in the metabolic rate of the Glanville fritillary butterfly. Journal of Experimental Biology, 213(7), 1042-1048. https://doi.org/10.1242/jeb.034132

Niitepõld, K., \& Boggs, C. L. (2015). Effects of Increased Flight on the Energetics and Life History of the Butterfly Speyeria mormonia. PLoS One, 10(10), e0140104. https://doi.org/10.1371/journal.pone.0140104

Niven, J. E., \& Scharlemann, J. P. W. (2005). Do insect metabolic rates at rest and during flight scale with body mass? Biology Letters, 1(3), 346-349. https://doi.org/10.1098/rsbl.2005.0311 
Odendaal, F. J., Turchin, P., Stermitz, F. R., Odendaal, F. J., Turchin, P., \& Stermitz, F. R. (1989). Influence of Host-Plant Density and Male Harassment on the Distribution of Female Euphydryas anicia (Nymphalidae ). Oecologia, 78(2), 283-288.

Ouin, A., Martin, M., \& Burel, F. (2008). Agricultural landscape connectivity for the meadow brown butterfly (Maniola jurtina). Agriculture, Ecosystems \& Environment, 124(3-4), 193-199. https://doi.org/10.1016/j.agee.2007.09.010

Ovaskainen, O., Luoto, M., Ikonen, I., Rekola, H., Meyke, E., \& Kuussaari, M. (2008). An Empirical Test of a Diffusion Model: Predicting Clouded Apollo Movements in a Novel Environment. The American Naturalist, 171(5), 610-619. https://doi.org/10.1086/587070

Ovaskainen, O., Rekola, H., Meyke, E., \& Arjas, E. (2008). Bayesian methods for analyzing movements in heterogeneous landscapes from mark-recapture data. Ecology, 89(2), 542-554. https://doi.org/10.1890/07-0443.1

Ovaskainen, O., Smith, A. D., Osborne, J. L., Reynolds, D. R., Carreck, N. L., Martin, A. P., ... Hanski, I. (2008). Tracking butterfly movements with harmonic radar reveals an effect of population age on movement distance. Proceedings of the National Academy of Sciences of the United States of America, 105(49), 19090-19095. https://doi.org/10.1073/pnas.0802066105

Patterson, T. A., Parton, A., Langrock, R., Blackwell, P. G., Thomas, L., \& King, R. (2017). Statistical modelling of individual animal movement: an overview of key methods and a discussion of practical challenges. AStA Advances in Statistical Analysis, 101(4), 399438. https://doi.org/10.1007/s10182-017-0302-7

Patterson, T. A., Thomas, L., Wilcox, C., Ovaskainen, O., \& Matthiopoulos, J. (2008). Statespace models of individual animal movement. Trends in Ecology \& Evolution, 23(2), 87-94. 
Polic, D., Fiedler, K., Nell, C., \& Grill, A. (2014). Mobility of ringlet butterflies in highelevation alpine grassland: effects of habitat barriers, resources and age. Journal of Insect Conservation, 18(6), 1153-1161. https://doi.org/10.1007/s10841-014-9726-5

R Core Team (2019). $R$ : A language and environment for statistical computing. R Foundation for Statistical Computing.

Ripley, B., Venables, W., \& Ripley, M. B. (2016). Package 'nnet.' R Package Version 7. Retrieved from https://cran.r-project.org/web/packages/nnet/nnet.pdf

Roland, J., Keyghobadi, N., \& Fownes, S. (2000). Alpine Parnassius butterfly dispersal:

Scali, V. (1971). Imaginal Diapause and Gonadal Maturation of Maniola jurtina (Lepidoptera: Satyridae) from Tuscany. Journal of Animal Ecology, 40(2), 467. https://doi.org/10.2307/3255

Schick, R. S., Loarie, S. R., Colchero, F., Best, B. D., Boustany, A., Conde, D. A., ... Clark, J. S. (2008). Understanding movement data and movement processes: Current and emerging directions. Ecology Letters, 11(12), 1338-1350. 
Schneider, C. (2003). The influence of spatial scale on quantifying insect dispersal: an analysis of butterfly data. Ecological Entomology, 28(2), 252-256. https://doi.org/10.1046/j.1365-2311.2003.00495.x

768

769

Schneider, C., Dover, J., \& Fry, G. L. A. (2003). Movement of two grassland butterflies in the same habitat network: the role of adult resources and size of the study area. Ecological Entomology, 28(2), 219-227. https://doi.org/10.1046/j.13652311.2003.00494.x

Schtickzelle, N., Joiris, A., Dyck, H. Van, \& Baguette, M. (2007). Quantitative analysis of changes in movement behaviour within and outside habitat in a specialist butterfly. BMC Evolutionary Biology, 7(1), 1-15. https://doi.org/10.1186/1471-2148-7-4

Schultz, C. B. (1998). Dispersal Behavior and Its Implications for Reserve Design in a Rare Oregon Butterfly. Conservation Biology, 12(2), 284-292. https://doi.org/10.1046/j.15231739.1998.96266.x

Schultz, C. B., \& Crone, E. E. (2001). Edge-Mediated Dispersal Behavior in a Prairie Butterfly. Ecology, 82(7), 1879. https://doi.org/10.2307/2680054

Schultz, C. B., Franco, A. M. a, \& Crone, E. E. (2012). Response of butterflies to structural and resource boundaries. Journal of Animal Ecology, 81(3), 724-734. https://doi.org/10.1111/j.1365-2656.2011.01947.x

Scott, J. A. (1974). Mate-Locating Behavior of Butterflies. American Midland Naturalist, 91(1), 103. https://doi.org/10.2307/2424514

Seidel, D. P., Dougherty, E., Carlson, C., \& Getz, W. M. (2018). Ecological metrics and 
methods for GPS movement data. International Journal of Geographical Information Science, 32(11), 2272-2293.

Shreeve, T. G. (1984). Habitat selection, mate location, and microclimatic constraints on the activity of the speckled wood butterfly Pararge aegeria. Oikos, 42(3), 371-377. https://doi.org/10.2307/3544407

Shreeve, T. G. (1992). Adult behaviour. In R. L. H. Dennis (Ed.), The ecology of butterflies of Britain (pp. 22-45). Oxford University Press.

Sih, A., Bell, A., \& Johnson, J. C. (2004). Behavioral syndromes: An ecological and evolutionary overview. Trends in Ecology \& Evolution, 19(7), 372-378. https://doi.org/10.1016/j.tree.2004.04.009

Singh, N. J., Börger, L., Dettki, H., Bunnefeld, N., \& Ericsson, G. (2012). From migration to nomadism: movement variability in a northern ungulate across its latitudinal range. Ecological Applications, 22(7), 2007-2020. https://doi.org/10.1890/12-0245.1

Skalski, G. T., \& Gilliam, J. F. (2003). A Diffusion-Based Theory of Organism Dispersal in Heterogeneous Populations. The American Naturalist, 161(3), 441-458. https://doi.org/10.1086/367592

Smith, J. N. M. (1974). The Food Searching Behaviour of Two European Thrushes. Behaviour, 48(1-4), 276-301. https://doi.org/10.1163/156853974X00363

Spiegel, O., Leu, S. T., Bull, C. M., \& Sih, A. (2017). What's your move? Movement as a link between personality and spatial dynamics in animal populations. Ecology Letters, 20(1), 3-18. https://doi.org/10.1111/ele.12708

Stevens, V. M., Trochet, A., Van Dyck, H., Clobert, J., \& Baguette, M. (2012). How is dispersal integrated in life histories: a quantitative analysis using butterflies. Ecology 
Stevens, V. M., Turlure, C., \& Baguette, M. (2010). A meta-analysis of dispersal in butterflies. Biological Reviews, 85(3), 625-642. https://doi.org/10.1111/j.1469185X.2009.00119.x

Takeuchi, T. (2010). Mate-locating behavior of the butterfly Lethe diana (Lepidoptera: Satyridae): do males diurnally or seasonally change their mating strategy? Zoological Science, 27(10), 821-825.

Thomas, J. (2010). Butterflies of britain and Ireland. British Wildlife Publishing.

Tinbergen, N. (1963). On aims and methods of ethology. Zeitschrift für Tierpsychologie, $20(4), 410-433$.

Tukey, J. W. (1949). Comparing individual means in the analysis of variance. Biometrics, 5(2), 99-114.

Turchin, P. (1991). Translating Foraging Movements in Heterogeneous Environments into the Spatial Distribution of Foragers. Ecology, 72(4), 1253-1266.

Van Swaay, C. A. M., Dennis, E. B., Schmucki, R., Sevilleja, C. G., Balalaikins, M., Botham, M., ... Carlisle, B. (2019). The EU Butterfly Indicator for Grassland species: 19902017: Technical Report. Butterfly Conservation Europe \& ABLE/EBMS.

Vande Velde, L., \& Van Dyck, H. (2013). Lipid economy, flight activity and reproductive behaviour in the speckled wood butterfly: on the energetic cost of territory holding. Oikos, 122(4), 555-562. https://doi.org/10.1111/j.1600-0706.2012.20747.x

Walters, R. J., Hassall, M., Telfer, M. G., Hewitt, G. M., \& Palutikof, J. P. (2006). Modelling dispersal of a temperate insect in a changing climate. Proceedings of the Royal Society B: Biological Sciences, 273(1597), 2017-2023. https://doi.org/10.1098/rspb.2006.3542 
Weimerskirch, H., Bonadonna, F., Bailleul, F., Mabille, G., Dell’Omo, G., \& Lipp, H.-P. (2002). GPS tracking of foraging albatrosses. Science, 295(5558), 1259.

Wickman, P.-C. (1985). The influence of temperature on the territorial and mate locating behaviour of the small heath butterfly, Coenonympha pamphilus (L.) (Lepidoptera: Satyridae). Behavioral Ecology and Sociobiology, 16(3), 233-238. https://doi.org/10.1007/BF00310985

Wiklund, C. (2003). Sexual selection and the evolution of butterfly mating systems. In C. L. Boggs, W. B. Watt, \& P. R. Ehrlich (Eds.), Butterflies, ecology and evolution taking flight (pp. 67-90). University of Chicago Press.

Williams, H. J., Taylor, L. A., Benhamou, S., Bijleveld, A. I., Clay, T. A., Grissac, S., ... Börger, L. (2020). Optimizing the use of biologgers for movement ecology research. Journal of Animal Ecology, 89(1), 186-206. https://doi.org/10.1111/1365-2656.13094

Woods Jr., W. A., Wood, C. A. L., Ebersole, J., \& Stevenson, R. D. (2010). Metabolic Rate Variation over Adult Lifetime in the Butterfly Vanessa cardui (Nymphalidae:

Nymphalinae): Aging, Feeding, and Repeatability. Physiological and Biochemical Zoology, 83(5), 858-868. https://doi.org/10.1086/656216

Zalucki, M. P., \& Kitching, R. L. (1982). The Analysis and Description of Movement in Adult Danaus plexippus L. (Lepidoptera: Danainae). Behaviour, 80(3-4), 174-197. https://doi.org/10.1163/156853982X00346

Zollner, P. A., \& Lima, S. L. (2005). Behavioral tradeoffs when dispersing across a patchy landscape. Oikos, 108(2), 219-230. 
854 Table 1. Coefficients ( \pm SEs) from the multinomial regression

\begin{tabular}{lcccc}
\hline & Intercept & Sex (male) & $\begin{array}{c}\text { Habitat (nectar- } \\
\text { rich) }\end{array}$ & Air temperature \\
\hline 3 (High-inactive) & - & - & - & - \\
1 (High-bask) & $-4.85(1.29)^{* * *}$ & $-0.33(0.36)$ & $1.93(0.76)^{*}$ & $0.08(0.05)$ \\
2 (High-flight) & $-0.42(1.03)$ & $3.48(0.49)^{* * *}$ & $-2.24(0.38)^{* * *}$ & $-0.07(0.05)$ \\
4 (High-nectar) & $-7.86(23.79)$ & $-0.79(0.33)^{*}$ & $9.91(23.77)$ & $-0.12(0.05)^{*}$
\end{tabular}

855 Coefficients show changes in log odd ratios of a time budget occurring in a cluster relative to

856 the baseline cluster for a unit change in the predictors. The baseline here is the inactive group

857 ('High-inactive'). Significance scores for coefficient estimates were produced using a two-

858 tailed Wald test.

$859 * P<0.05 ; * * * P<0.001$.

860

861 
862 Table 2. Coefficients from the multinomial regression of clustering within nectar-rich

863 habitats

\begin{tabular}{lcccc}
\hline & \multicolumn{2}{c}{ Female } & \multicolumn{2}{c}{ Male } \\
& Intercept & Insolation & Intercept & Insolation \\
\hline High-inactive & - & - & - & - \\
High-bask & $-1.01^{* * *}$ & $2.17 \times 10^{-6}$ & $-1.67 * * *$ & $2.43 \times 10^{-5}$ \\
High-nectar & $-1.5^{* * *}$ & $9.46 \times 10^{-6 * * *}$ & $-3.67 * * *$ & $2.28 \times 10^{-5 * * *}$ \\
High-flight $\dagger$ & -- & -- & $-3.8^{* * * *}$ & $2.56 \times 10^{-5 * * *}$ \\
Mixed $\dagger$ & -- & -- & $-1.93^{*} * *$ & $1.02 \times 10^{-5 * * *}$
\end{tabular}

864 Coefficients show changes in log odd ratios of a time budget occurring in a cluster relative to

865 the baseline cluster for a unit change in the predictors. The baseline here is the inactive group

866 ('High-inactive'). Significance scores for coefficient estimates were produced using a two-

867 tailed Wald test.

$868 * * * P<0.001$

$869 \dagger$ Cluster only observed in males.

870

871

872 
873 Figure 1. The average duration of behaviours within clusters and the proportion of

874 individuals grouped in clusters across sex and habitat types. Left-hand panels (a-d) show

875 cluster groups with bars representing the mean proportions of time the behaviour was

876 performed in the cluster, middle panels show the proportion of the different sexes grouped in

877 the cluster, and the right-hand panels show the proportion of the habitat types (nectar-poor

878 and nectar-rich) in which the cluster was observed. 'Ovi' refers to oviposition an activity rare

879 across all clusters.

880

881

Figure 2. Movement parameters in selected cluster groups. (a) Step distances and (b) turning angles for males in the 'high-nectar' versus 'high-flight' clusters. (c) Step distances and (d) turning angles for females in the 'high-nectar' versus 'high-inactive' clusters. Pairings were chosen as examples where both step distances and turning angles were significantly different between the groups.

Figure 3. Comparison of displacement predictions from the random-walk models. (a) Males and (b) females.

Figure 4. (a) The optimal amount of time butterflies should spend in exclusive search $T_{s p}$, given the rate of resource diminishment $c$ and the relative search effectiveness of exclusive search over normal behaviour $B$. (b) The optimal time when $c=0$ and (c) the optimal time when $c=1$ representing no resource diminishment and total resource diminishment at maximal life span, respectively. 